\title{
Research of Casting Moulding of Epoxy Resin Composites Reinforced with High-Strength Fibres during the Manufacturing Operations
}

\author{
Lucia Knapčíková ${ }^{1}$, Annamária Behúnová ${ }^{1}$ \\ ${ }^{1}$ Technical University of Košice, Faculty of Manufacturing Technologies with the seat in Prešov, \\ Bayerova 1, 08001 Prešov, Slovakia
}

\begin{abstract}
In general, epoxy resins are known for their excellent adhesion, chemical and thermal resistance, unique mechanical properties and excellent electrical insulators. The various fibres are incorporated into epoxy resin matrix materials. With the prepared samples, the fibre tests are passed. The results of the investigation are also taken into account due to the strength of the connection between the fibre and the matrix. The aim of our research is the preparation and subsequent testing of epoxy-based composite materials during their manufacturing operations, specifically by casting technology. The properties of fibre-reinforced composites depend significantly on the choice of fibre and matrix, and how they are combined, the fibre-matrix ratio, the fibre length, its orientation, the thickness of the composite and the presence of a bonding agent to improve fibrematrix bonding.
\end{abstract}

Keywords - Epoxy resin, High-strength fibres, Composites, Manufacturing, Environment.

\section{Introduction}

Epoxy adhesives are most often prepared by the condensation of epichlorohydrin and a hydroxy compound (polyalcohols or more functional phenols) [1].

DOI: $10.18421 /$ TEM94-22

https://doi.org/10.18421/TEM94-22

Corresponding author: Lucia Knapčíková, Technical University of Košice, Faculty of Manufacturing Technologies with the seat in Prešov, Slovak Republic. Email: lucia.knapcikova@tuke.sk

Received: 10 August 2020.

Revised: 19 October 2020.

Accepted: 26 October 2020.

Published: 27 November 2020.

(c) BY-NC-ND@ 2020 Lucia Knapčíková \& Annamária Behúnová; published by UIKTEN. This work is licensed under the Creative Commons AttributionNonCommercial-NoDerivs 4.0 License.

The article is published with Open Access at www.temjournal.com
When these compounds are mixing, the amine groups react with the epoxide groups to form a covalent bond [1]. Each amine group can react with the epoxy group so that the resulting polymer is cross-linking and is thus relatively stable and robust [2]. During curing, by-products are not split off, and only small total polymerization shrinkage occurs, this property is used mainly in production with the high required accuracy [2]. Cured epoxy resins have the best mechanical and primarily electrical properties, excellent electrical insulating properties in a wide range of temperatures, they are resistant to water and solutions of alkalis and acids [3]. Chemical resistance increases with the chain length of the molecule and the degree of crosslinking. Thermoset polymers are usually available as liquid resins or as solid particles, powders or granules [3]. Many liquid resin systems require two or more components to be mixed to initiate crosslinking or curing. For example, a liquid epoxide often requires a polymeric resin (e.g., based on bisphenol A and epichlorohydrin) and a hardener such as a polyamide. The resin and hardener are mixed to initiate a crosslinking reaction [1],[3].

Similar to thermoplastic resins, some thermosetting resins are commercially available as the reaction proceeds as the viscosity of the resin increases [3]. At this point, excess water is removed from the reaction under reduced pressure to obtain a viscous resin that is soluble in the solvent (known as the A-phase resin) [4]. The A-phase resin is cooled to a solid and ground to a fine powder. Ingredients such as fillers, colorants or lubricants are mixed with the powder. The powder is then processed on heated mixing rollers, where some crosslinking takes place. If the polymer is almost insoluble in the solvent but still meltable under heat and pressure, the reaction is terminated to obtain a B-stage resin [4]. The B-stage resin is cooled and coarsely ground into granules or pellets. The resin is heated until it liquefies and then consolidated in a mould, for example by injection or compression [4]. With time and temperature, the liquefied B-stage resin crosses to a solid [3], [4]. The curing method is shown graphically in Figure 1. From the graphical representation, when the liquid resin is cured under temperature-controlled conditions, the viscosity increases with time. 


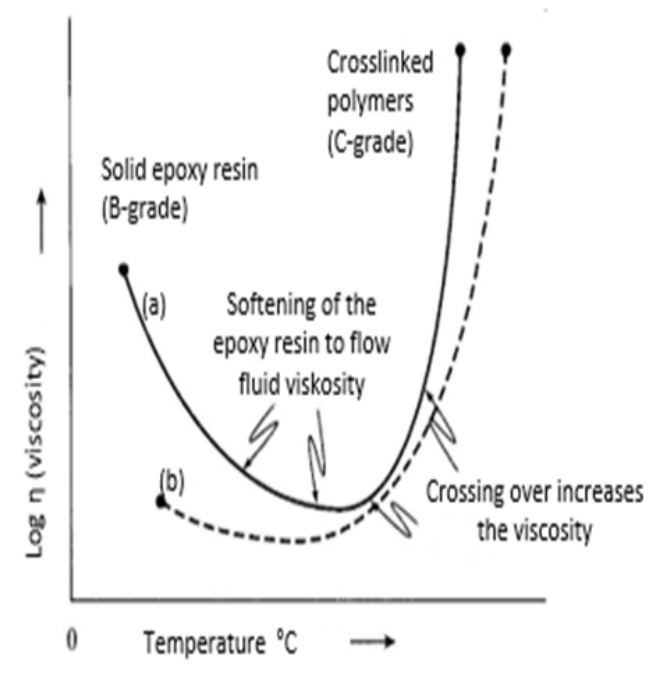

Figure 1. Influence of time and temperature on hardening of epoxy resin a)Vulcanization of the polymer to B-grade b)Vulcanization of the epoxy resin at a controlled temperature [1]

Once the thermosets are formed, they cannot be remelted. This makes the press very difficult to clean, which is the main reason why thermosets are often moulded in a device that is simpler than that used for thermoplastics [3].

\section{State of the Art}

Fibre-reinforced composite structures have become highly competitive engineering materials in recent years, and they have gradually replaced conventional metallic and other polymeric materials in many important industries [3]. Epoxy-based composite materials are used in load-bearing structures such as aircraft, military vehicles, ships, structures and offshore structures due to their advantageous mechanical, physicochemical properties and high strength-to-weight ratio [5]. Improving fire resistance has been given top priority to increase market penetration and given the current strict aviation legislation and other safety measures [5], [6]. In the aerospace, automotive or other areas of preference, epoxy matrix composite materials are expanding due to their large specific properties [3]. However, in these areas, it is not enough to use these materials, but rather to ensure that their use is beneficial in terms of reliability and durability, regardless the application or environmental conditions [7].

\section{Manufacturing of Epoxy Resin Composites- Experimental Work}

\subsection{Epoxy Resin as a Matrix}

Epoxy resins (EP resins) are compounds that have at least one epoxy group, also called glycidyl group or ethylene group, in their molecule [4].

The following properties make EP resins particularly suitable for use as a matrix system [3], [4]:

- Excellent mechanical and thermal behaviour.

- Good adhesion with the reinforcing fibre.

- The adjustability of the reaction mass in a wide viscosity range between solid and liquid by mixing with plasticizers.

- Acceleration of the curing process at different temperatures by a selection of the curing agent.

- Curing by polyaddition, i.e. without splitting off low molecular weight products.

- Especially low shrinkage after reaching the gelling point.

Table 1. Handling and mechanical properties of 105/206 Epoxy resin [4]

\begin{tabular}{|l|l|}
\hline $\mathbf{1 0 5} / 206$ Epoxy resin & $\begin{array}{l}\text { 105 Epoxy resin } \\
\text { 206 Slow Hardener }\end{array}$ \\
\hline Mix ratio & $5: 1$ \\
\hline Working time (thin film) & 90 to 110 minutes \\
\hline Cure to a solid (thin film) & 10 to 15 hours \\
\hline Cure to working strength & 1 to 4 days \\
\hline $\begin{array}{l}\text { Minimum recommended } \\
\text { temperature }\end{array}$ & $16^{\circ} \mathrm{C}$ \\
\hline Hardner SHORE D & 83 \\
\hline Tensile strength & $50,3 \mathrm{MPa}$ \\
\hline Tensile elongation & $4,5 \%$ \\
\hline $\begin{array}{l}\text { Tg by Differential } \\
\text { scanning calorimetry }\end{array}$ & $52{ }^{\circ} \mathrm{C}$ \\
\hline Standard internal & $\mathrm{ISO} 527-2 \mathrm{E}$ \\
\hline $\begin{array}{l}\text { Laboratory } \mathrm{C} \\
\text { temperature }\end{array}$ & $60 \%$ \\
\hline Humidity & \\
\hline
\end{tabular}

105/206 forms a high-strength, moisture-resistant solid with excellent adhesion and barrier properties. It wets and binds to wood fibre, glass fibre, reinforcing fabrics, foam and other composite materials and various metals [4].

\subsection{High-strength Fibres Characterization}

By our research was tested selected highstrength fibres, as follows: 


\section{Glass fibre (GF)}

Glass is a ceramic material with a particular property - below a transformation range (glass transformation temperature) the toughness is so high (supercooled liquid) that the body first transforms into another plastic and finally into a solid brittle state [7]. Silicic acid $\mathrm{SiO}_{2}$ is mainly used as the glass former. The excellent mechanical properties of glass fibres are based on the strong covalent bonds between silicon and oxygen [8]. The addition of various metal oxides changes the structure of the network, and thus the properties of the glass fibre.

\section{Carbon fibre (CF)}

If higher demands are placed on the mechanical properties, the use of carbon fibres is advantageous [6]. Exist several types of carbon fibres on the market, with the features such as high tenacity ("high tenacity HAT"), high stiffness ("high modulus HM"), high strain fibres (HS), as well as intermediate modulus (IM), which have a particularly high elongation at break (about 2\%). E-modulus are higher than that of HT fibres. There are also ultrahigh modulus (UHM) fibres [8].

\section{Aramid fibre (AF)}

Similar to carbon fibres, the fibres have a negative coefficient of thermal expansion in the longitudinal direction, i.e. they become shorter and thicker when heated [6], [7]. Their specific strength and modulus of elasticity are significantly lower than those of carbon fibres. In combination with the positive coefficient of expansion of the matrix resin, highly dimensionally stable components can be produced [3], [5]. Compared to carbon fibre reinforced plastics, the compressive strength of aramid fibre composites is significantly lower. A distinction is made between two modifications, which differ in particular in their different modulus of elasticity:

- "Low Modulus" - "Low Modulus" (NM) - tensile strength is $2800 \mathrm{MPa}$ and E modulus is 5900 $\mathrm{MPa}$.

- "High modulus" - "High modulus" (HM)- tensile strength $2900 \mathrm{MPa}$ and E-modulus $12700 \mathrm{MPa}$.

Both modifications have a density of 1,44-1,45 g.cm${ }^{3}[8]$.

\section{Cordenka}

Cordenka is a material with excellent properties. Excellent volume resistance makes Cordenka, which is very popular for industrial applications [6],[9],[10]. Composites, reinforced with Cordenka have an outstanding balance between stiffness and toughness [11]. Cordenka is used in the automotive industry as a fabric insert for tyres, but also as a reinforcement material in tubes and other industrial applications.

Table 2. Mechanical properties of selected high strength fibres [7, authors own processing]

\begin{tabular}{|l|c|c|c|}
\hline \multicolumn{1}{|c|}{ Fibres } & $\begin{array}{c}\text { E-modul } \\
{[\mathbf{G P a}]}\end{array}$ & $\begin{array}{c}\text { Tensile } \\
\text { strength } \\
{[\mathbf{G P a}]}\end{array}$ & $\begin{array}{c}\text { Elongation } \\
\text { at break } \\
{[\mathbf{\%}]}\end{array}$ \\
\hline Glassfibre & 50 & 1,5 & 3,5 \\
\hline Carbonfibre & 150 & 2,5 & 1,5 \\
\hline Aramidfibre & 100 & 2,0 & 2,0 \\
\hline Cordenka & 833 & 20 & 13,0 \\
\hline
\end{tabular}

The following Table 3 describes the processing characteristics of selected types of high-strength fibres.

Table 3. Characteristic of selected high strength fibres [authors own processing]

\begin{tabular}{|l|c|c|c|}
\hline \multicolumn{1}{|c|}{ Fibres } & $\begin{array}{c}\text { Length } \\
{[\mathbf{m m}]}\end{array}$ & $\begin{array}{c}\text { Weight } \\
{[\mathbf{g}]}\end{array}$ & $\begin{array}{c}\text { Density } \\
{\left[\mathbf{g . c m}^{-3}\right]}\end{array}$ \\
\hline Glasfibre & 370 & 0,1129 & 2,5 \\
\hline Carbonfibre & 342 & 0,0682 & 1,8 \\
\hline Aramidfibre & 426 & 0,0187 & 1,45 \\
\hline Cordenka & 316 & 0,0786 & 1,5 \\
\hline
\end{tabular}

\subsection{Casting Moulding of Composite Materials}

A mould measuring $80 \times 80 \times 5 \mathrm{~mm}$ was used. When fixing individual types of fibres, we proceeded as follows:

- Paper-board likes a frame for cutting shapes.

- Fix the base on the paper, so that this 3-5 $\mathrm{mm}$ is hung in shape.

- Fix the paper in the form, close the form.

The method of placing the fibres in the mould is shown in Figure 2. 


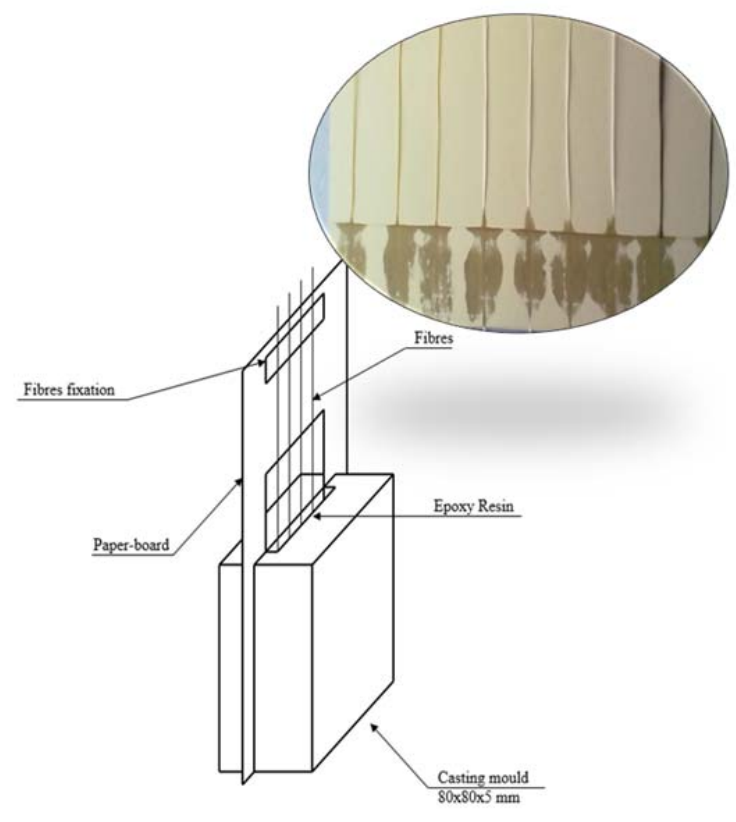

Figure 2. Preparing of test samples used casting mould with detailed filler [authors own processing]

- Mix resin, if possible free of bubbles,

- Pour resin into the mould,

- Allow the epoxy resin to cure in a drying cabinet at $80^{\circ} \mathrm{C}$.

\section{Results and Discussion}

The continuous fibres in the epoxy matrix give the best properties. The fibres transfer mechanical loads, the matrix transfers loads to the fibres, it is malleable and tight, and protects the fibres from damage during handling and the environment [13]. The operating temperature and processing conditions of the composite depend on the matrix material. The longer the fibres, the more effective the reinforcement at load transfers, but the shorter the fibres are easier to process and therefore cheaper. Figure 3 shows the tensile characteristics of the tested aramid fibres in an epoxy matrix. After the tensile test [11], it can be seen that the aramid fibres are at a specified max. Loading forces of 2.59 N.mm from the die were torn off. It was due to imperfect adhesion between the fibres and the matrix.

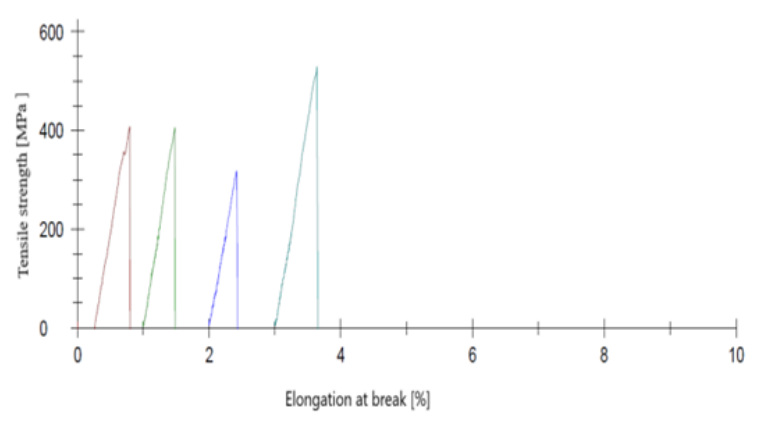

Figure 3. Aramid fibres in the epoxy resin matrix after the tensile test
Figure 4 is an illustration of the tensile test of carbon fibres in an epoxy matrix, at a force of 37.06 N.mm. From the diagram, one can see the material samples have reached max. tensile strength of 896.9 $\mathrm{MPa}$ and elongation at break $0.78 \%$.

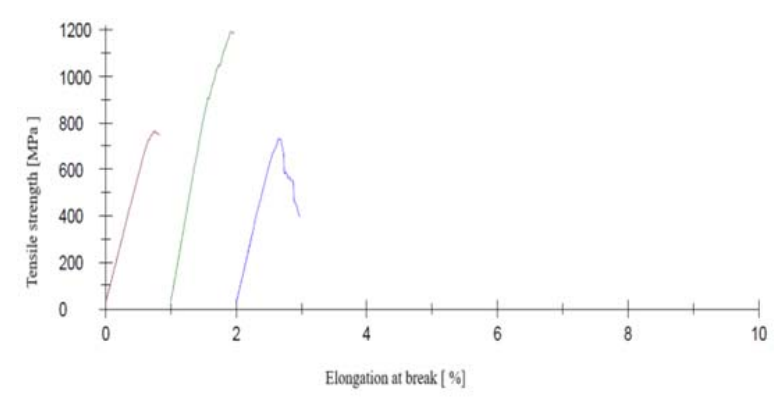

Figure 4. Carbon fibres in the epoxy resin matrix after the tensile test

The glass fibres (Fig. 5) which were deposited in the epoxy resin matrix have a tensile strength value of $2441.4 \mathrm{MPa}$ and an elongation at break value of $2.33 \%$ after the tensile test. The loading force was 295.18 N.mm.

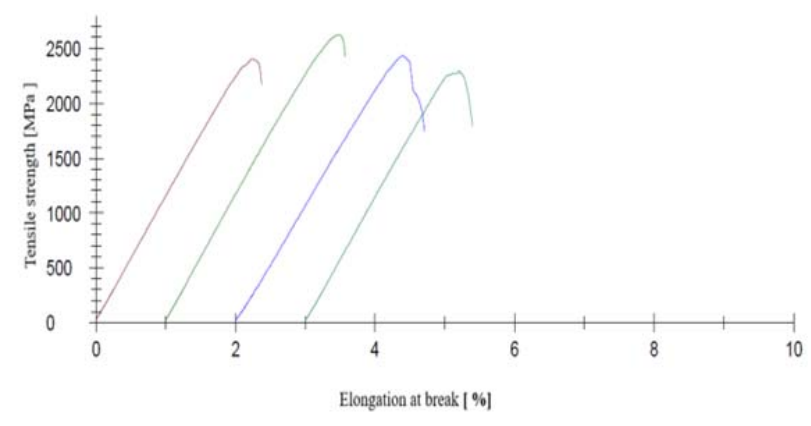

Figure 5. Glass fibres in the epoxy resin matrix after the tensile test

Cordenka fibres (Fig.6), which are commonly used as reinforcement in tyres, had a tensile strength of 412.7 $\mathrm{MPa}$ and an elongation at break of $7.97 \%$ after a tensile test. The loading force, in this case, was 233.98 N.mm.

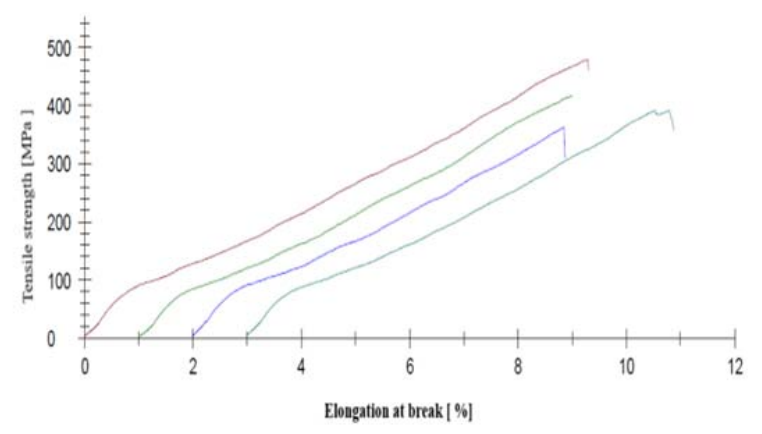

Figure 6. Cordenka fibres in the epoxy resin matrix after the tensile test 
The increasing thickness of the composite material leads to a reduction in the strength of the composite [14]. The modulus of strength [15], as the probability of the presence of defects increases.

Mechanical properties obtained after the tensile test are presented in the Table 4.

Table 4. Mechanical properties of selected high strength fibres

\begin{tabular}{|c|c|c|c|}
\hline $\begin{array}{c}\text { Fibres in Epoxy } \\
\text { Resin }\end{array}$ & $\begin{array}{c}\text { Tensile } \\
\text { strength } \\
{[\mathbf{M P a}]}\end{array}$ & $\begin{array}{c}\text { Elongation } \\
\text { at break } \\
{[\text { \%o] }}\end{array}$ & $\begin{array}{c}\text { E-Modul } \\
{[\mathbf{M P a}]}\end{array}$ \\
\hline \hline Aramidfibre (AF) & 414,9 & 0,58 & 69276 \\
\hline Carbonfibre (CF) & 896,9 & 0,78 & 130145 \\
\hline Glassfibre (GF) & 2441,4 & 2,33 & 107367 \\
\hline Cordenka & 412,7 & 7,97 & 8985 \\
\hline
\end{tabular}

Thus, it is clear from the previous graphics that the glass fibres in the epoxy matrix have the highest tensile strength value and, conversely, the smallest Cordenka fibres. On the contrary, at the elongation at break values, it is the Cordenka fibres with the highest elongation at break value, namely $7.97 \%$, and the aramid fibres reached the value of $0.58 \%$. Environmental impact [16], such as fatigue load, humidity and temperature, reduces the allowable strength [12]. Mechanical properties obtained after the tensile test are presented in the Table 4.

\section{Conclusion}

Depending on our investigation, we can say that glass fibres are characterized by high strength at low cost; carbon fibres have very high strength, stiffness and low density. Aramid fibres have high strength and low density, they prevent the spread of fire, they are permeable to radio waves and Cordenka fibres, on the other hand, they a high value of elongation at break.

Epoxy-based composite materials excel in their mechanical properties and chemical resistance. They are used wherever we require durable materials. They are characterized by high adhesion to various substrates and excellent strength.

We see the applicability of epoxy-based composite materials in the production of light structural elements in aviation, land transport, in the production of sports equipment, such as golf clubs, oars, boats and rackets, also in the manufacturing of several components in the automotive industry. As for our future direction of the research in the field of epoxybased composite materials, we want to focus on specific elements in the automotive industry.

\section{Acknowledgements}

This work has been supported by the project VEGA 1/0440/18"Research of a technical system for the identification of diameters and vibrations of workpieces during manufacturing operations in the automotive industry”.

\section{References}

[1]. Hirai, Y., Hamada, H., \& Kim, J. K. (1998). Impact response of woven glass-fabric composites-II. Effect of temperature. Composites Science and Technology, 58(1), 119-128.

[2]. Rajaei, M., Kim, N. K., \& Bhattacharyya, D. (2018). Effects of heat-induced damage on impact performance of epoxy laminates with glass and flax fibres. Composite structures, 185, 515-523. DOI.org/10.1016/j.compstruct.2017.11.053.

[3]. Ling, H., Battley, M., \& Allen, T. (2015). Tensile, compressive and impact performance of high volumefraction resin transfer moulded flax and glass fibre epoxy laminates for sporting applications. In 20th International Conference on Composite Materials.

[4]. 105 Epoxy Resin/206 Slow Hardener. (2020). Retreived from: www.westsystem.com, [accessed: 18 July 2020].

[5]. Mandičák, T., Mesároš, P., \& Tkáč, M. (2018). Impact of management decisions based on managerial competencies and skills developed trough BIM technology on performance of construction enterprises. Pollack Periodica, 13(3), 131-140.

[6]. Farzana, R., Rajarao, R., \& Sahajwalla, V. (2016). Characteristics of waste automotive glasses as silica resource in ferrosilicon synthesis. Waste Management \& Research, 34(2), 113-121. doi:10.1177/0734242X15617010.

[7]. Barry, C. M., \& Orroth, S. A. (2000). Processing of thermoplastics. Modern Plastics Handbook, 1, 5-1.

[8]. Liptáková, T., Alexy, P., Gondár, E., \& Khunová, V. (2009). Polymérne technické materiály. Žilinská univerzita, Žilina, 65-80.

[9]. Straka, M., Taušová, M., Rosová, A., Cehlár, M., Kačmáry, P., Sisol, M., ... \& Farkas, C. (2020). Big Data Analytics of a Waste Recycling Simulation Logistics System. Polish Journal of Environmental Studies, 29(3), 2355-2364.

[10]. Zgodavova, K., Mihalikova, M., Hurna, S., Straka, M., \& Miklos, V. (2018). Rationalization of the material consumption in a chemical-technological process of forming. Przemysl chemiczny, 97(2), 200204.

[11]. ISO, B. (1996). 527-2: 1996. Plasticsdetermination of tensile properties-part 2: test conditions for moulding and extrusion plastics. British Standards Institution, 1-14.

[12]. Elalaoui, O., Ghorbel, E., Mignot, V., \& Ouezdou, M. B. (2012). Mechanical and physical properties of epoxy polymer concrete after exposure to temperatures up to $250 \mathrm{C}$. Construction and Building Materials, 27(1), 415-424.

http://dx.doi.org/10.1016/j.conbuildmat.2011.07.027 
TEM Journal. Volume 9, Issue 4, Pages 1488-1493, ISSN 2217-8309, DOI: 10.18421/TEM94-22, November 2020.

[13]. Zaborowski, T., Jurko, J.(2019). Assessment of transformation effects in cutting process. Institute of Scientific Research and Expertise, p.130, ISBN 9788364249969.

[14]. Fu, S. Y., Feng, X. Q., Lauke, B., \& Mai, Y. W. (2008). Effects of particle size, particle/matrix interface adhesion and particle loading on mechanical properties of particulate-polymer composites. Composites Part B: Engineering, 39(6), 933-961.

http://dx.doi.org/10.1016/j.compositesb.2008.01.002
[15]. Dong Y, Chaudhary D, Ploumis C and Lau K-T. (2011). Correlation of mechanical performance and morphological structures of epoxy micro/nanoparticulate composites. Composites Part A: Applied Science and Manufacturing. 42(10):14831492.

http://dx.doi.org/10.1016/j.compositesa.2011.06.015

[16]. Behun, M., Gavurova, B., Tkacova, A., \& Kotaskova, A. (2018). The impact of the manufacturing industry on the economic cycle of European Union countries. Journal of competitiveness, 10(1), 23. 